\title{
Curar e recrear em águas termais: um diálogo etnográfico entre Portugal (Termas de São Pedro do Sul e Termas da Sulfúrea) e Brasil (Caldas da Imperatriz)
}

\section{Maria Manuel Quintela}

\section{(2) OpenEdition}

\section{Journals}

Edição electrónica

URL: http://journals.openedition.org/aa/1151

DOI: 10.4000/aa. 1151

ISSN: 2357-738X

\section{Editora}

Programa de Pós-Graduação em Antropologia Social (UnB)

Edição impressa

Data de publição: 1 dezembro 2011

Paginação: 169-194

ISSN: 0102-4302

\section{Refêrencia eletrónica}

Maria Manuel Quintela, «Curar e recrear em águas termais: um diálogo etnográfico entre Portugal (Termas de São Pedro do Sul e Termas da Sulfúrea) e Brasil (Caldas da Imperatriz)», Anuário Antropológico [Online], v.36 n.1 | 2011, posto online no dia 24 novembro 2015, consultado o 28 abril 2021. URL: http://journals.openedition.org/aa/1151 ; DOI: https://doi.org/10.4000/aa.1151

\section{(c) (i) (3)}

Anuário Antropológico is licensed under a Creative Commons Atribuição-Uso Não-Comercial-Proibição de realização de Obras Derivadas 4.0 International. 


\title{
Curar e recrear em águas termais: um diálogo etnográfico entre Portugal (Termas de São Pedro do Sul e Termas da Sulfúrea) e Brasil (Caldas da Imperatriz)
}

\author{
Maria Manuel Quintela \\ Escola Superior de Enfermagem de Lisboa
}

\section{Apresentação}

O termalismo em Portugal e no Brasil é uma actividade que se desenvolveu entre a medicina e o turismo, à semelhança do que ocorreu noutros países europeus (Weisz, 2001; Mackman, 1998). Contudo, o seu processo histórico de formação seguiu caminhos diferentes nos dois países, em função dos sistemas médicos que o enquadram, bem como da relevância dada a cada uma das actividades que o termalismo intersecta, medicina e/ou turismo, e das tensões existentes entre elas. ${ }^{1}$

Em Portugal e no Brasil as práticas termais são classificadas de diferentes modos de acordo com os respectivos sistemas de saúde nacionais. Em Portugal, à semelhança do que se passa nalguns países europeus, estas práticas são comparticipadas pelo sistema nacional de saúde e enquadradas no aparelho biomédico. Já no Brasil, elas são comparticipadas pelo SUS (Sistema Único de Saúde) como práticas complementares e/ou integrativas desde 2006. Resultantes de processos sociais e históricos particulares de cada país (Quintela, 2004, 2008, 2011), estas diferenças permitem pensar o termalismo enquanto actividade reguladora e de desenvolvimento das práticas termais, bem como geradora de terapias que se têm adequado a novas configurações sociais no campo da saúde, onde a noção de bem-estar é cada vez mais central. Com efeito, é com base nesta categoria que surge um conjunto de novas terapias associadas às tradicionais termas, terapias estas que vão para além do tratamento da doença (Nairandas \& Bastos, 2011) e passam a focalizar-se na prevenção. É disto exemplo a legislação portuguesa de 2004 relativa à regulação do termalismo, pois inclui as duas vertentes - o "segmento de bem-estar" e o segmento de "termalismo clássico".

Pensar na relação entre medicina e turismo e nas suas finalidades leva-nos a questionar dimensões da experiência que, aparentemente, à luz de uma visão redutora da biomedicina, se não são inconciliáveis, serão pelo menos de associação 
ambígua. A medicina tem como finalidade curar a doença e aliviar o sofrimento. O turismo é uma actividade que visa promover o lazer, o recrear, o prazer. O meu interesse inicial pelo estudo do universo termal nasceu justamente da curiosidade que me despertaram estas aparentes contradições, notórias no próprio terreno etnográfico. Em 1995, data da minha primeira incursão etnográfica nas Termas de S. Pedro do Sul (Portugal), estas eram um lugar que se construía em ambiguidades: a de receber doentes - por ter água termal - mas de querer simultaneamente receber turistas; a de ter como santos de culto a Senhora da Saúde e o São Martinho; a de pertencer à Região Vinícola Dão-Lafões, cruzando assim água e vinho, a primeira associada à cura e o segundo à diversão; a coexistência de um balneário ${ }^{2}$ - lugar de tratamento - e uma discoteca de nome Pecados - lugar de recreação. Não era fácil classificar o lugar perante o conjunto de actividades que aí se desenrolavam e as pessoas que aí se encontravam. Escrevi então:

"Local de férias? Local de tratamento? O ambiente fazia lembrar ao mesmo tempo um espaço balnear marítimo e um espaço terapêutico. O primeiro era sugerido pelos calções, pelas toalhas de praia sobre os ombros, bem como pelas vendas de boias e fatos de banho; o segundo, pela quantidade de bengalas e de corpos envolvidos em toalhas turcas, xailes, gorros, roupões e luvas. Mas, então, que locais são estes? Cura-se? Folga-se? Recreia-se e cura-se! Pode-se sofrer e recrear simultaneamente?" (Quintela, 1999:5).

O que seriam afinal umas termas? O que faziam as pessoas nas termas? Era um lugar aparentemente organizado por categorias de doença e de lazer, em que as dimensões recreativa e terapêutica coexistiam na organização social do espaço e do tempo. Terreno privilegiado, sem dúvida, para reflectir sobre tópicos como a dor, o sofrimento, a doença, a saúde e também o lazer. Por outro lado, tornava-se um desafio estudar estas dimensões num cruzamento entre duas áreas disciplinares em que raramente tinha sido efectuado: a antropologia da saúde e a antropologia do turismo.

O estudo das Termas de São Pedro do Sul permitia ainda compreender o processo de formação do termalismo em Portugal, uma vez que elas são consideradas as primeiras termas portuguesas, associadas à fundação da nação, e um seu balneário foi edificado pelo primeiro monarca português, D. Afonso Henriques, e tem o seu nome. Eram, além disso, também as termas mais frequentadas do país. ${ }^{3}$ 
A partir das questões levantadas neste primeiro estudo, ${ }^{4}$ realizei depois uma etnografia comparativa sobre práticas termais em Portugal, noutras termas (Cabeço de Vide), e no Brasil (Caldas da Imperatriz, Santa Catarina). A escolha desta estância termal brasileira teve como principal justificação o facto de esta ser considerada a mais antiga do Brasil, mandada construir ainda no reinado de D. João VI. Parecia por isso o local mais indicado para acompanhar o processo de formação do termalismo brasileiro (Quintela, 2004, 2008) e para permitir uma comparação diacrónica com o caso português.

Pretendo neste artigo estabelecer um diálogo entre a primeira etnografia que realizei em Portugal e a que realizei no Brasil. Tal permitirá discutir comparativamente a relação entre curar e recrear como dimensões constituintes da formação das estâncias termais e do termalismo em torno da água enquanto eixo estruturante das práticas termais.

Tomarei como estratégia narrativa a apresentação do primeiro estudo de caso e das questões então colocadas, dialogando com a etnografia realizada na estância termal brasileira. Pretendo explorar novas questões que a comparação suscitou, estabelecendo interlocução com a biomedicina, a antropologia da saúde e alguns estudos das ciências sociais sobre termalismo inexistentes à data da minha primeira etnografia (1999).

\section{A formação das estâncias hidrominerais e do termalismo: entre a medicina e o turismo}

A descoberta e o uso das águas termais com fins terapêuticos deram origem a cidades que foram designadas, conforme o período histórico e os contextos nacionais, como estâncias hidrominerais, hidroclimáticas, de cura, termais. As estâncias termais começam por organizar-se enquanto locais de vilegiatura na medida em que o termalismo, como terapêutica para doenças crónicas, implica a repetição cíclica de uma estadia relativamente prolongada nesses locais (Quintela, 1999, 2004). Em geral, a estadia prolongada para tratamento faz-se nos hospitais. Estes espaços "oficiais” de cura são habitualmente instituições "fechadas" (Goffman, 1966; Foucault, 1991), regulamentadas por um conjunto de normas que estruturam um período de evitamento social e que se inscrevem no corpo “doente" durante o internamento. Os comportamentos são ordenados pela doença ou pelos sinais que ela manifesta, inscritos no corpo. Constrói-se assim uma identidade - a do doente - a quem são atribuídos papéis e comportamentos associados a uma performance de sofrimento. Estar doente, neste contexto, é a negação do prazer e do bem-estar. As termas portuguesas são também espaços de cura, concessionados e cientificamente legitimados pela biomedicina 
através da criação de estabelecimentos termais específicos (os balneários). Tratase assim de um sistema terapêutico cujo fulcro é a água, que é apropriada como dispositivo de cura, mas também como motivo de lazer e recreação. As estâncias termais acabam por organizar-se em função desta dupla apropriação da água.

Se a instituição hospitalar, centrada na doença, cria uma separação entre o indivíduo e o mundo social, a organização de actividades de lazer pressupõe a sociabilidade, centrando-se na oferta de práticas de diversão facilitadoras de estados de prazer. As termas configuram-se por isso plasticamente entre os modelos da instituição hospitalar (Goffman, 1966) e da organização recreativa (MacCannell, 1976). Analisar a formação das estâncias termais à luz destes dois modelos pode parecer paradoxal, mas é exactamente aí que reside a especificidade daqueles lugares e o desafio a pensá-los e a discutir algumas categorias analíticas estabelecidas sobre terapias e sistemas médicos, designadamente a biomedicina.

A legislação portuguesa de 1919 é indicativa da relação entre estas duas actividades ao determinar que em cada estância mineral existisse um médico director clínico, com a especialização em hidrologia médica e que teria como função, para além de vigiar a higiene da povoação termal, promover o lugar do ponto de vista turístico (Quintela, 2004, 2008, 2011). As Termas de São Pedro do Sul são um exemplo disto.

Já no Brasil, Caldas da Imperatriz foi um hospital transformado em hotel termal..$^{5}$

\section{Memórias, banhos e tratamentos: curar e recrear nas Termas de São Pedro do Sul}

As Termas de São Pedro do Sul estão situadas no centro de Portugal e são a estância portuguesa mais frequentada. Foram recentemente palco de novas reestruturações. Há uma grande assimetria entre a população residente e a população flutuante - os hóspedes e os termalistas. ${ }^{6}$ Foi em torno da água termal que a localidade se edificou. A água, sulfurosa, brota à temperatura de $68^{\circ}$ centígrados e o lugar da sua nascente é um ponto de atracção turística. Os habitantes locais inventaram a este propósito um hino, a que chamam o "hino dos escaldados".

Para se poder realizar tratamento, nesta tal como noutras estâncias portuguesas, é necessário obter primeiro prescrição médica. Os tratamentos e/ou banhos são realizados nos balneários, estabelecimentos regulados medicamente e onde se efectua um conjunto de técnicas balneoterápicas como, por exemplo, duches, banhos de imersão em cabines individuais ou em piscina. Aqueles que aqui se dirigem para efectuar um "tratamento" são designados por aquistas, 
banhistas, termalistas, curistas e doentes conforme a época. Os balneários não possuem espaço para hospedagem. Esta faz-se em hotéis, pensões e casas de hóspedes.

Os hóspedes (nome mais frequentemente empregue pelos escaldados - habitantes das termas - para denominar aqueles que lá vão fazer tratamento), "banhistas" ou "aquistas" desempenham um papel central na edificação das memórias locais e dos espaços para eles construídos - o espaço do tratamento e o espaço da hospedagem. As memórias balneares compõem-se e reproduzem-se em torno das actividades realizadas pelos "hóspedes", "banhistas" ou "aquistas" e pela relação estabelecida com os "escaldados" nos espaços onde decorrem os tratamentos e a recreação. De acordo com os grupos sociais, encontramos traços distintivos que nos permitem identificar memórias geracionais constituídas em volta dos objectos e da relação social que com eles é estabelecida. Consoante as diferentes identidades, assim as memórias se centram em objectos (banheiras, roupas) e em eventos distintos (refiro-me aqui especialmente à história de alguns edifícios, como hotéis e balneários, e às actividades de cariz recreativo ou terapêutico que neles se realizavam, como bailes, concertos, cinema, banhos e tratamentos).

As memórias balneares dependem das motivações de cada actor social e da sua identidade de grupo: hospedeiros, hóspedes, funcionários, hoteleiros e comerciantes. Os eventos são lembrados e é dada maior ou menor ênfase àqueles recreativos e/ou terapêuticos em conformidade com a pertença social relativa aos grupos de idade e de género. Assim, para "os de S. Pedro", as termas representavam o lugar onde eram realizadas as festas e onde, no Verão, havia raparigas "novas" e de "fora" e as senhoras "iam tomar chá", ou ainda o lugar dos "banhos". Os locais evocam a sazonalidade do trabalho, a animação do Verão - pois "o Inverno era muito triste" - a "qualidade dos hóspedes", a construção de alguns edifícios, a relação com a água quente e com os tratamentos. Os aquistas relembram as filas de espera para os tratamentos, o balneário, os médicos, os estabelecimentos hoteleiros e a animação. Quanto aos funcionários do balneário - denominados "banheiras" ou "banheiros" - lembram alguns "banhistas". Os hoteleiros referem os "hóspedes". Destaca-se, porém, um denominador comum: são lembrados os bailes e assinalados os traços distintivos das práticas recreativas e balneares, desde a roupa que se usava, a classe de tratamento, o local de hospedagem até a própria chegada dos hóspedes.

Era no Balneário da Rainha D. Amélia, mais precisamente no átrio, que se iniciava o rito de passagem de "turista" 7 a "aquista", através da inscrição na consulta médica. Aí o médico ou a médica passava "a prescrição" que permitia o acesso ao Centro Termal, momento que marcava a passagem do indivíduo a 
aquista, banhista. Contudo, no Balneário “velho”, a dimensão terapêutica cruzava-se com outras duas: a recreativa e a religiosa. Estas podiam, de imediato, ser observadas no átrio e são indicativas da trifuncionalidade deste edifício: quer pela diversidade de informação inscrita na parede, expressa na cor, nos diferentes letterings, nos conteúdos das respectivas mensagens, quer pelo mobiliário, bancos brancos de madeira evocando um hospital, quer ainda pelas funções dos funcionários que ali se encontravam. Conforme registei na segunda metade da década de 1990, no mês de Agosto,

quando entrava neste edifício, eu tinha a sensação de estar perante uma manta de retalhos humana. Havia simultaneamente pessoas que, conforme o local a que se dirigiam, procuravam actividades típicas de diferentes esferas da vida social. Se se dirigiam ao guichet - situado do lado direito de quem entra podiam inscrever-se na consulta médica, ou pedir informações no Posto de Turismo $^{8}$ (a distinção residia, apenas, nas/os funcionárias/os a quem se dirigiam). Mas alguém que se encaminhasse para o lado esquerdo poderia ser um simples curioso ou admirador do artesanato senegalês (Quintela, 1999:121).

Quem se encaminhasse à parede oposta à porta central poderia ler um cartaz informativo do horário da missa, uma vez que ali se encontra a porta que dá acesso ao primeiro andar, onde estava instalada, provisoriamente, a igreja de Nossa Senhora da Saúde, enquanto a nova igreja estava em construção. Ali era celebrada diariamente missa por padres eles próprios aquistas, que beneficiavam, em troca da prestação deste serviço, de direito a tratamentos gratuitos.

A coexistência neste espaço das dimensões terapêutica, recreativa e religiosa era reiterada pela diversidade de cor e das mensagens das inscrições que se viam nas paredes: desenhos alusivos aos sete sacramentos feitos por crianças; cartazes da exposição de artesanato senegalês; informações sobre o procedimento para a inscrição nas consultas médicas e, ainda, um cartaz com a palavra "Silêncio"9 - tal como acontece frequentemente nos locais associados a actividades terapêuticas e religiosas. Além do sentido da visão, também o da audição apontava a coexistência das dimensões acima referidas. Quem entrava no átrio para visitar a exposição ou aguardava a consulta médica podia ouvir, entre as 18 e as 19 horas, cânticos religiosos, sinal de que decorria a missa.

O espaço religioso estava separado física e simbolicamente por uma porta que dá acesso à igreja, situada no primeiro andar. Como me disse um médico, referindo-se a uma época anterior, "esta era a porta que separava o Balneário do Casino e os dois lados: o tratamento e a animação”. 
A ambiguidade da coexistência destas dimensões, agudizada pela vizinhança e a separação em que se encontram, produz discursos contraditórios, que são foco de tensão social local, sobretudo por parte de alguns médicos, para quem as duas dimensões devem permanecer separadas, pois "ali não é para lazer, mas para tratar; se querem fazer animação, que façam longe do balneário, pois também não há turismo em cima de um hospital”.

Se, por um lado, esta distinção tem sido reiterada historicamente pelo discurso médico, como se constata nos relatórios clínicos, por outro lado, as práticas contradizem-na, sendo ilustrativa a dupla função dos próprios funcionários do balneário: "banheiros" durante o dia e empregados do casino à noite, no bar ou no bengaleiro. No entanto, não são só os médicos que acentuam a separação destas dimensões, mas também alguns hospedeiros das casas de aluguer, como a título exemplificativo fazia o Sr. Pontes, que se insurgia com o barulho produzido durante a noite pela música num bar de gente nova: "pois isto são umas termas, é para descansar, são doentes!".

É a porta que opera a separação física e simbólica das dimensões terapêuticas e recreativas, ou será o horário diurno ou nocturno que introduz a distinção? $\mathrm{O}$ dia era para os "tratamentos" e a noite para o casino, como está ainda presente nas memórias de alguns aquistas e residentes. É o caso da Sra. Ariana, de 85 anos, que não revisitava as termas desde os 15 anos, e que guardava delas duas recordações principais: do casino, onde tinha aprendido "a dançar o minuete" ("um salão muito bonito onde eu namoriscava um rapazito"), e da água quente ("toda a vida me lembrei da água quente a sair do chão, onde não havia nenhuma protecção, e o medo que eu tinha que aí caísse alguma criança...”). Mas, por vezes, a alternância entre o dia e a noite não introduziam a clivagem entre estes tratamentos e a recreação. Como lembra o Sr. Mendes, de 68 anos e que não vinha a estas termas havia 30 anos:

no tempo em que os tratamentos eram feitos no Balneário da Rainha D. Amélia, era necessário irmos para a bicha muito cedo, às 4 horas, para comprar as senhas. E então, depois de andarmos na farra, de ter ido ao pão quente, íamos directamente para o balneário. Nessa altura a bicha chegava a dar a volta ao jardim, e o último a chegar recebia um raminho de oliveira. Agora não, é tudo diferente!

Porém, o espaço onde se realizam os "tratamentos", e que descreveremos no ponto seguinte, estava bem demarcado, sem ambiguidades aparentes, num edifício cujos objectivos eram meramente terapêuticos: o Centro Termal. O centro 
- também chamado "Balneário Novo"10 - dista aproximadamente cem metros do "Balneário Velho". Aqui os aquistas eram designados, nomeadamente pelos funcionários mais novos, por “utentes”, e não mais por “doentes”, mudança sintomática de uma nova terminologia que se introduzia também nas instituições de saúde portuguesas e que pretendia retirar do doente o cunho de "paciente", sujeito passivo de cuidados, para passar a ser actor.

Se a actividade central que caracteriza e organiza o ciclo termal - os tratamentos - se efectua em torno destes edifícios, é também no seu perímetro que se situam as "nascentes" de água termal e se desenrolava um conjunto de dimensões da vida social decorrentes da estadia neste lugar - que contribuíam para a integração dos hóspedes, por meio da rede de sociabilidades que aí se estabeleciam entre banhos.

\section{Os "tratamentos": entre "banhos" e "brincadeiras"}

Embora as funcionárias do balneário se referissem a alguns aspectos penosos do trabalho "no tempo do Balneário Velho" - o número excessivo de horas de trabalho, a "grande disciplina" - o que elas ressaltavam eram as dimensões lúdicas que existiam no estabelecimento. As memórias focavam-se nos mediadores do trabalho, digamos que as suas ferramentas - as "banheiras". Estas eram um dos objectos recorrentes nas memórias tanto dos residentes como dos hóspedes e banhistas, e elas próprias introduziam traços sociais distintivos, materializados nas classes de tratamento, como relembra a Sra. D. Mariana:

Entre a 1. ${ }^{\mathrm{a}}$, a $2 .^{\mathrm{a}}$ e a $3 .^{\mathrm{a}}$, a diferença estava nas banheiras, pois na 1. ${ }^{\mathrm{a}}$ as banheiras eram de mármore e o chão, em vez de cimento, era de azulejos... Mas havia muitas pessoas que compravam bilhetes de 1. e depois iam para a 2. ${ }^{\mathrm{a}}$, ou porque gostavam mais das empregadas ou do ambiente.

Quando era abordada a disciplina do balneário, dois registos eram mencionados em simultâneo, a disciplina e o lúdico. Uma antiga funcionária do balneário recordava, a propósito de uma aquista: "no Balneário Antigo, na 2. classe havia uma senhora que cantava, dançava e fazia teatro, era uma alegria quando ela chegava!". Contudo, não só as aquistas eram lembradas como "animadoras"; também as próprias funcionárias o eram: "havia mesmo uma empregada do balneário que perguntava às aquistas se podia cantar, e cantava enquanto fazia tratamentos!". São várias as descrições do espaço do balneário como um sítio de "barulho" e de "animação", onde a "disciplina era apenas para os funcionários". A mesma pessoa recordava o tratamento desigual para com os empregados: 
Não era possível andar com brincadeiras... Havia lá uma senhora, que era a chefe do pessoal, de grande categoria... andava tudo ali na linha! E havia um médico que era todo mesuras para as senhoras, mas para as funcionárias era muito exigente.

A Sra. Laurinda recordava também alguns episódios menos agradáveis quanto à disciplina imprimida por aquela senhora. Todavia, não deixava de referir os aspectos agradáveis e lúdicos do trabalho ("havia senhoras que à tarde iam para, ao pé de nós, contar anedotas”) e descrevia também como, apesar de estarem marcados espacialmente, os géneros se cruzavam, tendo como mediadores a "água quente" e os equipamentos onde esta deslizava. Um dos episódios que esta senhora recordava era o das brincadeiras com os duches e com alguns banhistas mais "atrevidos". Relatou o caso de um médico novo, de Coimbra, que estava fazendo tratamento e que todos os dias se lhe dirigia pedindo-lhe para lhe "dar um duche”: "Eu depois disse: 'Ó minha senhora, ele é que o pediu. Ele queria um duche e eu dei-lho'”. E acrescentava, divertida, que alguns homens que estavam a fazer tratamento - "no lado dos homens" - iam ao lado das senhoras: "iam lá para se rir e para brincar, mas aquele tomou um duche que se consolou. Saiu todo molhado". Mas quando perguntei se eram pessoas doentes ou vinham só fazer banhos, aí não havia dúvidas quanto à identidade dos banhistas:

Não! Eram mesmo doentes... Precisavam! Não eram muito de vias entupidas, ${ }^{11}$ mas havia um tratamento que faziam à sífilis. Eram umas massagens com uma pomada. Faziam aquelas massagens. Havia mesmo pessoas especializadas nisso, e depois tomavam banho de imersão. Dizem que fazia muito bem à sífilis (Quintela, 1999:15).

E assim eram lembrados alguns tratamentos que se faziam "no tempo do Balneário Velho", como era o caso das irrigações vaginais utilizadas para as "inflamações”. E eram evocadas pela Sra. D. Laurinda algumas senhoras que se submeteram a este tipo de tratamento e as razões que as levavam a tal - como o caso de uma senhora que não engravidava, mas que após o tratamento com estas irrigações "começou a ter filhos", e o de uma outra, "de Lisboa, que teve uma menina". E ainda relembrava uma senhora espanhola:

Já não foi comigo que ela fez tratamento, foi com a minha tia que Deus tem. Era espanhola, também conseguiu ter uma menina. Durante muitos anos ela veio, e depois, quando foi aquela grande guerra em Espanha, aquela senhora deixou de vir. 
Um das doenças em que era utilizado este tratamento era a sífilis. O tratamento não era ministrado apenas no Balneário, sendo-o, no entanto, com alguma discrição. É lembrada uma senhora "que tinha uma malinha" e andava pelas pensões e hotéis a aplicar a "pomada":

Ela andava pelos hotéis, pelas pensões, tinha uma malinha e uma bata branca, e andava pelos hotéis e fazia as massagens. Eram umas fricções, uma espécie de massagens. Davam-nas aqui nesta parte de baixo, era nas pernas.

Já o banho era feito no balneário e antecedia a aplicação da "pomada", "pois o banho abria os poros e depois davam aquelas massagens".

Além das memórias da doença associada à sífilis, a Sra. Laurinda recordava as crianças que faziam tratamento (naso-faríngeo). Lembrava que havia também crianças - umas "meninas" - cujo pai lhe ia "entregar" para fazerem os "tratamentos" e com as quais estabelecia cumplicidade, permitindo que elas não os fizessem e que assim "pudessem ir para a brincadeira".

Já algumas crianças locais, "para não andarem na brincadeira nas férias", trabalhavam no balneário, o que correspondia em vários casos ao início de uma carreira profissional. Há então, nos funcionários autóctones, um trajecto profissional comum que se inicia em criança - aos 9 anos - as raparigas na buvette ${ }^{12} \mathrm{e}$ os rapazes como grooms. Na buvette, o único requisito "era saber ler os números", para poderem administrar aos aquistas a graduação exacta de água. Aos rapazes da mesma idade cabia a função de groom, inscrita na roupa que usavam - "uma farda amarela com um boné" - e que consistia em transportar os "doentes" que não se podiam mobilizar, do local onde estavam hospedados até ao balneário, numa cadeira de rodas de madeira. De acordo com a idade, assim iam mudando as funções dentro do balneário, e a sua relação com o corpo. Desta forma, após estas actividades iniciais, passavam a distribuir as "fichas" - que introduziam uma ordem no tempo dos banhistas. Seguidamente passavam para a zona dos banhos, mas apenas para "encher" e "lavar" as "banheiras", pois administrar os duches só acontecia por volta dos 18 anos.

Esta divisão de tarefas por grupos de idades evidenciava assim uma distinção marcada entre um corpo público e privado. Contava a rir a Sra. Laurinda, então com 80 anos, um episódio de quando tinha os seus 15, 16 anos: "As outras senhoras diziam-me: 'Ó Laurinda, anda cá pôr água quente'; se lá estavam as senhoras nuas eu não ia lá!”. Esta relação com a nudez era uma das razões apontadas por algumas funcionárias, que entretanto tinham outras funções, como justificação para "não gostar de dar duches". Havia porém um saber que era 
construído com a idade e transmitido pelas pessoas "mais velhas", situação, aliás, que serve de termo de comparação com o que acontece hoje com a formação acelerada dos funcionários actuais: "Não é como agora em que qualquer uma dá banhos ou duches; não, era preciso saber e demorava anos a aprender!”.

Todavia, havia outros tipos de banhos administrados no balneário que eram lembrados, para os quais não era necessária nenhuma preparação, pois não implicavam a intervenção directa dos funcionários. Eram estes os "banhos higiénicos" e os "banhos santos". Como a própria denominação indica, os banhos têm funções diferentes de acordo com o uso social da água termal, a que correspondem distintos rituais, que acentuam as propriedades de transmutabilidade deste líquido. Deste modo, a função atribuída à água quente mudava no espaço balnear de acordo com o dia da semana e com a época do ano. Os domingos eram o momento para o banho higiénico, denominação dada ao banho do qual os autóctones e a população de S. Pedro do Sul podiam usufruir. ${ }^{13}$ Para os primeiros este era gratuito. Havia apenas um funcionário que ficava com a chave e abria as portas do balneário. Os casais podiam até tomar banho em quartos de duas banheiras. Contudo, uma vez por ano era chegada a altura do "banho santo", no dia de S. Pedro (29 de Junho ${ }^{14}$ ). E aí o banho decorria de uma forma diferente, pois não era já a higiene que estava em causa, mas o facto de a "bênção" daquele banho "valer por sete". Havia porém quem discordasse:

O Banho Santo era num dia de Junho. Vinham tomar banho ao rio, era gente da vertente do Douro. Lembro-me das excursões, os homens em ceroulas e as senhoras com camisas de dormir, com roupa interior. Havia uma tradição, não era no Balneário!

Sobressai nas memórias balneares a relação estabelecida entre hóspedes e hospedeiros, marcada por clivagens sociais expressas no tipo de alojamento utilizado e nos marcadores sociais inscritos no corpo. O que permanece é um espaço que tem como palco a relação com o corpo, quer seja numa performance de tratamento ou de recreação, onde a água é protagonista. Ela condiciona, conforme a actividade profissional que se desempenha, a ênfase, numa ou noutra dimensão, na forma como se recorda e vive a época balnear nas Termas de S. Pedro do Sul. Ela também constrói socialmente o lugar como um destino terapêutico na busca da "cura de águas" e um destino turístico na busca da natureza e na fuga da cidade. ${ }^{15}$ Foi isto que encontrámos também nas Caldas da Imperatriz, no Brasil. 


\section{O Hotel Caldas da Imperatriz: um lugar terapêutico}

Isto é muito terapêutico! Porque as pessoas vêm de grandes cidades, e estão correndo atrás dos horários, estão atravessando cidades para chegar ao seu trabalho. Aqui não, aqui não tem nada disso. É comer, é beber, tomar banho e dormir, passear, pronto! Quer dizer, o hotel cria um ambiente de paz, de relaxamento! (António, 65 anos, Curitiba).

O Hotel Caldas da Imperatriz fica situado nas Caldas da Imperatriz, no município de Santo Amaro, estado de Santa Catarina. O lugar deve a sua existência à descoberta de águas termais com propriedades terapêuticas e à construção de um hospital termal na primeira metade do século XIX. Este hospital, que teve o nome da Imperatriz, foi reconvertido em hotel na década de 1920 (Quintela, 2004, 2008). Nestas termas brasileiras, as práticas termais decorrem no espaço de um hotel, não estando incluídas no sistema oficial de saúde brasileiro, tal como anteriormente referimos. ${ }^{16} \mathrm{O}$ uso da água termal tem estado neste contexto associado a práticas classificadas como "medicinas alternativas" ou "complementares”. Os espaços termais não são aparentemente medicalizados, não são hospitalizados, isto é, não são regulados medicamente, ao contrário do que acontece nas termas portuguesas estudadas.

Não há médico no espaço balnear termal e, consequentemente, não é necessária prescrição médica para efectuar os "banhos" - os tratamentos. O estabelecimento dos banhos coincide com o estabelecimento de hospedagem, o hotel, contrariamente ao que acontece nas termas portuguesas. No hotel termal Caldas da Imperatriz, os hóspedes, designação aqui utilizada, podem fazer uso dos banhos livremente nas banheiras existentes em seis cabines individuais durante a estadia termal e/ou temporada, designação local.

Se em Portugal a designação para o período de permanência numas termas é a quinzena, uma vez que corresponde ao número de dias de que os aquistas necessitam para fazer os tratamentos, nas Caldas da Imperatriz, bem como noutras termas brasileiras, a expressão usada é a temporada (ou estação). Esta corresponde ao período também considerado necessário pelos hóspedes, e encontramo-la nalguns textos de médicos que escreveram sobre o uso das águas minerais como o período indicado para fazer um tratamento numa estância termal. Mas aqui não nos deparamos com homogeneidade nos discursos sobre a duração de uma temporada. Nestas caldas, varia entre uma semana e um mês. Esta variabilidade parece estar associada, por um lado, ao facto de este espaço não estar, aparentemente, medicalizado e, por outro lado, a idiossincrasias e a questões geracionais. 
Para os mais velhos, a temporada corresponde aos 21 dias, acrescidos de uma semana para descansar (do tratamento), concepção que encontramos presente em termas portuguesas e europeias. Para os mais jovens, por limitações de ordem laboral, esta varia entre uma semana e dez dias, uma vez que o tempo de férias não permite mais. Os casais mais jovens evocam como razão para uma estadia de três ou quatro dias a vontade de "descansar do foleiro da praia", dedicando assim o último período de férias ao "descanso".

E em que consiste a temporada? A temporada implica fazer o uso da água como tratamento. Esta é assim denominada por aqueles que pretendem alcançar nesta estadia, através do uso da água termal e/ou mineral, um objectivo terapêutico, seja ele a cura, o alívio da dor ou a prevenção. Deste modo, nesse período os dias são organizados em função dos banhos. É esta a unidade temporal de referência - "antes do banho", "depois do banho" - o que denota uma diferença relativamente ao que verificámos em Portugal, onde é usada a designação "tratamento" - "antes do tratamento", "depois do tratamento".

O objectivo terapêutico da temporada é conseguido não apenas através do uso da água - em banhos e bebida - mas também de um conjunto de actividades que o complementam, como a alimentação, o sono, o exercício físico e também aquelas que possuem uma dimensão religiosa e espiritual. A este conjunto poderemos chamar em tal contexto, por similitude com as terminologias turísticas, um pacote termal, composto por banhos, refeições, passeios, repouso e ainda a bênção de saúde do Frei Hugolino. Estas dimensões estão presentes tanto nos fundamentos da Higiene, enquanto disciplina médica orientadora das práticas de vida do quotidiano, como nos fundamentos da teoria hipocrática da Água, Ares e Lugares. Elas são, igualmente, as dimensões organizadoras de uma estadia neste espaço para aqueles que não têm explicitamente um objectivo terapêutico ou não permanecem toda uma temporada, mas apenas um fim de semana.

A organização do dia termal é feita pelos hóspedes e os banhos não estão sujeitos a uma estrutura regulada por um dispositivo médico-sanitário que aponte para a hospitalização (Zola, 1972) da estadia termal. O espaço termal, neste caso entendido aqui como aquele relativo ao hotel, não é um "espaço disciplinar" (Foucault, 1991) em que se destaque o controlo sobre o uso do corpo, como acontece num hospital ou até nos balneários portugueses estudados. Nestes, para além de haver uma tentativa de "disciplinar o espaço", com indicações precisas da função e dos papéis de cada um (dos funcionários aos aquistas), há regras sobre o uso do corpo, relativas ao traje considerado próprio - o fato de banho - ou ao modo como são feitos os tratamentos (como a pessoa se deve colocar na banheira), de acordo com a prescrição médica. Já no Hotel Caldas 
da Imperatriz, as normas dizem apenas respeito aos horários das refeições e ao não uso de "traje de banho" no refeitório, ou ao silêncio que deve ser respeitado, pedidos feitos em cartazes.

Não podemos, de acordo com a observação realizada, afirmar que se trata de um processo de hospitalização, mas antes da incorporação por parte dos hóspedes de discursos medicalizados sobre como gerir o quotidiano (B. Turner, 1996), o que se reflecte nas suas práticas durante a estadia termal, a "temporada". Esta organiza-se nas dimensões referidas pelo senhor António: banhos, comer, descansar e desintoxicar num lugar concebido como terapêutico. E, nessa medida, a estadia termal é também concebida por alguns hóspedes como um programa de desintoxicação da "civilização", tal como o era no final do século XIX, ou como é apresentado actualmente nalguns folhetos turísticos portugueses e brasileiros - a estadia termal seria "um regresso à Natureza", e que se encontra na base das novas concepções dos lugares termais como lugares de "bem-estar". A água termal gera um lugar terapêutico porque permite recriar o quotidiano e a vida através de uma água que pelas suas propriedades virtuosas, na percepção de alguns hóspedes, para além de relaxar, tratar e energizar, "adianta" - um ano de vida em condições de saúde, retomando velhas concepções sobre as águas termais como o elixir da juventude, contrariamente a alguns termalistas portugueses que as usam, sobretudo, com a finalidade de "atrasar".

\section{As águas tratam; “não curam”, “atrasam”: concepções de saúde, doença, lazer e envelhecimento}

Nas termas portuguesas estudadas, sendo a "água" um dos elementos que entram na construção destes lugares como um destino terapêutico, é recorrente a afirmação feita pelos aquistas de que "a água não cura, atrasa, empata, empaleia!". O que de imediato sugere a questão - "atrasa" o quê?

O entendimento desta questão é variável: para uns é a doença e, neste caso particular, é referido o reumatismo; para outros, o "caruncho" da velhice. Daí a resposta - atrasa o desenvolvimento da "história natural" da doença, tal como ele é conceptualizado no modelo biomédico, sendo este também responsável pela construção social da "velhice" como associada a um estado patológico. Deste modo, podemos compreender que a expressão acima citada seja empregue, também, no sentido de "atrasar" o desenrolar "natural" da vida - a velhice - permitindo que a vida se prolongue em melhores condições. As metáforas utilizadas pelos termalistas no discurso sobre o corpo são analogias com a "máquina” e, desta forma, utilizando a mesma lógica, poderemos dizer que a água é o "óleo" que permite regenerar a "máquina", e o sítio termal é a "oficina” de reparação. 
Uma das formas de reparar a "máquina” é diminuindo os estados de não funcionalidade dos ossos gastos e do mal-estar provocado pelas dores do reumatismo. E este, vivenciado enquanto doença crónica, não é suposto ser curado, mas sim tratado. Neste sentido, os aquistas justificam por que a água não cura, mas apenas atrasa. Ela é concebida como um medicamento natural que substitui os anti-inflamatórios: “a água não cura, mas alivia as dores!”. Encontramos entre estes aquistas, sobretudo mulheres rurais, noções de tratamento termal que nos permitem sugerir que há nesses discursos e práticas concepções sobre a saúde e a doença que incluem também uma noção de prevenção. Para todos os efeitos, aquilo que é procurado, embora não explicitado no discurso, é também o bem-estar.

Nas termas portuguesas de S. Pedro do Sul, tal como nas Termas da Sulfúrea, regista-se uma perspectiva diferente da dos hóspedes das Caldas da Imperatriz relativamente ao efeito que as águas produzem sobre os anos de vida. Para uns "atrasa-os", para outros "adianta-os", ou seja, encontramos duas concepções da doença, da velhice e do tratamento e da estadia termal, tal como do lugar onde estas práticas se desenvolvem (Quintela, 2008, 2011). Se nas termas de S. Pedro do Sul e nas da Sulfúrea os tratamentos e os banhos se processam num balneário em edifícios regulamentados medicamente e a hospedagem se faz em lugares separados do lugar de tratamento, nas Caldas da Imperatriz o hotel é ao mesmo tempo local de hospedagem e de banhos.

Analisemos então as práticas termais e as suas motivações nestes contextos etnográficos para compreendermos as actividades que os sustentam à luz dos modelos hospitalar (Goffman, 1996) e recreativo (MacCannell, 1976). O "doente”, referido no contexto português como aquista, banhista ou hóspede, faz um internamento voluntário por um período de tempo que varia de acordo com o lugar e as possibilidades, em locais particulares designados como termas ou caldas - e nisto consiste a estadia termal, a "quinzena".

Os processos de cura, no senso comum, são frequentemente associados a espaços de recolhimento designados nos sistemas oficiais de saúde como hospitais, que são também, por excelência, lugares para a expressão do sofrimento. Nestes estabelecimentos, enquanto "instituições fechadas", usualmente não há campo para o lúdico e a recreação, porquanto são regulamentados por um conjunto de normas que estruturam um período de evitamento social e que se inscrevem no corpo "doente" durante o internamento. Os comportamentos são ordenados pela doença. São regulamentados o horário e o número de visitas, as horas das refeições, da higiene e do sono, e ainda a forma como se usa o corpo, por exemplo, quanto ao vestuário (nuns casos não se pode utilizar a roupa pessoal, noutros apenas se podem vestir "trajes de dormir"). 
Enquanto a instituição hospitalar cria uma separação entre o indivíduo e o mundo social a que ele pertence, as organizações recreativas tomam forma a partir do pressuposto de que uma sociabilidade intensa, vivida sobretudo em lugares aprazíveis, frequentemente adjectivados como "calmos" e com "boas paisagens", gera estados de prazer, de divertimento, lúdicos. Apresentada a equação deste modo, parece não nos restar outra solução que não pensar em curar e recrear como dois opostos inconciliáveis. No entanto, como a natureza humana é mais criativa do que lógicas do tipo maniqueísta, há práticas sociais que conjugam estas dimensões no espaço e no tempo. São disso exemplo as práticas termais, tal como já tivemos a oportunidade de mostrar na etnografia realizada sobre as Termas de S. Pedro do Sul (Quintela, 1999). Como é feita essa conjugação?

Como o próprio termo indica, as práticas termais têm a sua expressão em lugares designados como termas, balneários ou caldas. A nomeação do lugar é, por vezes, coincidente com a do estabelecimento, isto é, dizer "vou às termas" pode significar vou ao estabelecimento termal ou vou para um lugar onde existe um balneário termal, o qual poderei ou não utilizar. Os balneários termais têm sido em Portugal estabelecimentos que funcionam à semelhança do modelo hospitalar. Só tem acesso aos banhos e restantes tratamentos, inclusive à ingestão das águas, quem submeter o seu estado de saúde a uma avaliação médica, através de uma consulta prévia. É neste acto que é prescrita a água mineral natural água termal - enquanto medicamento, razão primeira do acto médico. Há aqui uma particularidade relativamente aos doentes que são alvo dessa prescrição no quadro de uma consulta hospitalar ou de um centro de saúde. Neste contexto, os doentes não buscam um diagnóstico médico, mas apenas a prescrição de um tratamento para os seus sintomas, diagnosticados por si como "males" da coluna, do "reumático", da "velhice", da "osteoporose", ou seja, procuram alívio para o seu mal-estar. Há nestas consultas, frequentemente, uma negociação entre médico e doente quanto à modalidade do tratamento a fazer, o que cria uma distinção em face de outros serviços de saúde.

Esta situação faz-nos pensar como classificar o tipo de medicina que aqui se pratica: será uma medicina centrada no sujeito, no diagnóstico ou na terapia (Luz, 2005)? Não será esta mais uma medicina centrada na terapia, em que há uma aproximação ao doente enquanto sujeito? E o aquista/banhista, um doente especial, aqui se torna ou não sujeito, segundo a geração, a classe social, a idade e o género? Nota-se nos aquistas/banhistas mais jovens e nos mais letrados uma maior incorporação do discurso oficial da saúde centrado nos estilos de vida saudável (não fumar, não beber, praticar exercício, seguir cuidados alimentares), ou seja, uma maior adesão aos consumos que promovem um “corpo saudável” e 
o "bem-estar". Nesta medida, o aquista/banhista torna-se sujeito numa prática que integra o "cuidado de si".

Esta é uma prática de consumo primário, tal como o são o ginásio, a natação, a dança e outros. Contudo, se nas termas portuguesas estudadas só é notado este cuidado com o corpo entre os mais jovens ou aqueles com maior capacidade económica, já nas termas brasileiras estudadas esta é uma preocupação transversal a todos os grupos etários e sociais, apesar de se manifestar em diferentes práticas de cariz geracional, caracterizadas por uma maior incidência em discursos e práticas New Age (Maluf, 1996) ou nas práticas tradicionais associadas ao "regime" entendido aqui como um conjunto de normas relativas à alimentação, à higiene, a práticas diárias de vida que foram concebidas enquanto tal desde a medicina hipocrática. Digamos que a "higiene", no sentido hipocrático do termo, foi precursora dos "estilos de vida saudáveis".

A procura de um "estilo de vida saudável" choca por vezes com os regulamentos de um espaço "hospitalizado". Foram várias as situações em que os aquistas pretenderam fazer a marcação dos tratamentos para o período da manhã, tal como acontecia nas Termas de S. Pedro do Sul (1997) ou na Sulfúrea (2003). Quando os funcionários administrativos o negavam, os aquistas insistiam e explicavam as razões desta preferência: "Olhe, sabe, é para poder ficar com o dia livre", ou "quero de manhã, que é para de tarde poder passear”. Estes argumentos pareciam enfurecer os receptores da mensagem, que de imediato respondiam inquisitorialmente: "Está aqui para se tratar ou para passear?". Do mesmo modo, encontrámos nas Termas de S. Pedro do Sul a afirmação da separação destes espaços por parte dos funcionários, quer na marcação dos tratamentos, quer na piscina termal. Nesta última pude igualmente ouvir da parte de ajudantes de fisioterapia, em face do barulho e da diversão aparentes dos aquistas, frases como "isto aqui não é para brincar, é para tratar!".

Por que é que se demarca tão enfaticamente a dimensão lúdica da dimensão terapêutica? Será então que "passear"/"brincar" e "tratar" são actividades mutuamente exclusivas? Não o são com certeza para aquistas ou para os hospedeiros, actores sociais protagonistas também da organização desta estadia.

Se é no balneário que estão os médicos e são feitos os tratamentos, é contudo nos locais de hospedagem que estes últimos são concluídos. As casas de hóspedes, as residenciais, as pensões são como que uma extensão do balneário, na medida em que após os tratamentos - os banhos - e o "arrefecimento" e o "repouso" no balneário (na sala de arrefecimento), o ritual do tratamento só termina com o "descanso" na cama (por períodos que variam entre os trinta minutos e as duas horas). Esta acção faz parte da terapia e visa a perda de suor e 
a "penetração da água no corpo", através da pele. Este é um dos momentos centrais do processo terapêutico termal, ao qual se atribui grande parte da eficácia do mesmo, tal como foi e é concebido nas teorias médicas termais desde o século XVII, que encontram os seus fundamentos na medicina hipocrática e humoral (Nutton, 2001).

Para David Greenwood (1984), o uso das águas minerais insere-se num tipo de "medicina naturalista" em que se conjugam a filosofia naturalista e a teoria humoral. Para este autor, a organização da vida diária de forma a criar um regime equilibrado faz parte do tratamento, que não é "intervencionista": "no balneário (termas) trata-se a pessoa total, porque o balneário é um meio-ambiente total. O descanso, a vida social, a falta de tensão são um refúgio do mundo e fazem parte da cura naturalista" (Greenwood, 1984:77-78). Greenwood acrescenta ainda que o balneário não se parece em nada com o hospital moderno. Será que esta afirmação se aplica às termas estudadas? Relembremos que nas termas portuguesas o balneário é o estabelecimento onde apenas se administram os tratamentos e se realizam as consultas médicas.

Nessas casas (de hóspedes) e nesses estabelecimentos (residenciais), descansa-se, dorme-se, come-se. Eles são o prolongamento do balneário - nas Termas de S. Pedro do Sul podíamos até observar nalgumas casas de hóspedes cartazes solicitando o silêncio, tal como acontece em estabelecimentos hospitalares e outras instituições de saúde. E é nesses espaços que se opera o ritual que faz pensar que uma prática terapêutica se metamorfoseia numa prática recreativa. É o momento em que os aquistas, neste contexto já designados como hóspedes, mudam de roupa após o descanso. Destapam-se, retiram as toalhas, os roupões, os xailes e vestem-se para passear, sair de casa, do quarto. A forma como as senhoras estão vestidas pode indicar-nos se elas vão permanecer nos locais onde estão hospedadas ou se vão passear. Estas mudanças significam que o tratamento, concluído pelo "suadouro", acabou. Terminou, então, usando uma analogia, a fase da hospitalização, e começa uma nova etapa: a recreação. E não será que uma e outra fase, que aparentemente são opostas, fazem parte do mesmo pacote, o tratamento termal? Não é esta a especificidade da prática terapêutica termal, que a recreação é um dos elementos da eficácia simbólica da cura?

As refeições nem sempre são tomadas no espaço onde se dorme, onde se descansa. Quando tal se verifica, este é um momento em que os aquistas se conhecem e trocam impressões sobre as respectivas experiências termais (que vão desde os banhos à hospedagem, aos passeios, às dores), conversas que se prolongam depois já no jardim, espaço de mediação e extensão entre o balneário e o "hotel". Fala-se sobre os tratamentos, sobre as doenças que para ali os 
direccionam e sobre as dores que os acompanham no quotidiano. Se quisermos fazer uma analogia com um internamento em estabelecimento hospitalar, verificaremos que é no respeitante à sociabilidade que se traça a principal fronteira de demarcação entre os dois tipos de internamento, hospitalar e termal. No primeiro, a sociabilidade é afectada ou até interdita, pois há horas previamente estabelecidas para o contacto social; no segundo, ela é promovida. Nalguns casos poderemos afirmar que há até, ou é procurada, uma exacerbação da sociabilidade. Este destino, assumido como terapêutico, traça novos figurinos, sobretudo para as mulheres que se encontram sozinhas nas termas (quer sejam casadas, viúvas ou solteiras).

A etnografia realizada nas termas portuguesas nos permitiu observar e constatar que para as mulheres, as frequentadoras mais numerosas, esta prática terapêutica permite sair dos espaços quotidianos da família e possibilita assim a afirmação da individualidade e da autonomia. São ilustrativas algumas das expressões pronunciadas: "é bom ter férias dos maridos", “aqui estou livre dos tachos”. Porém, este não é um tempo de total isolamento, em termos físicos, das famílias. Aos fins-de-semana podemos observar as famílias (maridos, filhos, netos) que se deslocam a estas termas para almoçar e fazer uma visita àqueles que estão em "reclusão" termal. Nalguns casos, pouco frequentes, pude observar que os maridos vêm passar o fim-de-semana. Segundo algumas mulheres, os maridos não as acompanham porque "estão a trabalhar", ou "porque é difícil entretê-lo aqui”, "isto aqui não há nada para ele fazer”.

No entanto, se a suspensão da vida social foi por nós associada ao quadro de um internamento hospitalar, também durante a estadia termal há uma interrupção da vida social, pois é introduzida uma mudança no quotidiano neste nível. No caso brasileiro, o período de internamento de algum modo sugere ainda a caracterização de Goffman (1966) das instituições fechadas de tipo "religioso". Lembremos que alguns desses hóspedes referem a estadia termal como um "retiro espiritual" que lhes permite "fugir do mundo". Ora, para o conseguir é necessário desencadear uma acção que inclua uma deslocação e introduza uma ruptura no quotidiano. Refiro-me aqui à viagem, associada preferencialmente a tempos de férias e de lazer, mas também a objectivos terapêuticos, o que se verifica historicamente, por exemplo, relembrando as palavras de Ramalho Ortigão (1875).

Do mesmo modo, as férias e o lazer são frequentemente classificadas como formas de "turismo", sendo este definido por alguns antropólogos como um tipo de lazer que estrutura o ciclo de vida, ao ser alternado com períodos de trabalho (Smith, 1989). Aquele que desenvolve essa actividade seria então o "turista", 
referido como uma pessoa desocupada, que voluntariamente visita um lugar longe de casa, com o objectivo de experimentar uma mudança, praticando actividades através das quais igualmente se introduz uma ruptura no quotidiano. No entanto, e na situação portuguesa em análise, mais do que de uma ruptura, trata-se de uma suspensão particular, de fazer um intervalo no sofrimento do quotidiano, tal como é expresso nas narrativas de vida que estas mulheres partilham com as colegas neste espaço. Contudo, se algumas das práticas do quotidiano que são indicadas ou sugeridas como as causas do sofrimento (o trabalho, as relações com a família ou a ausência destas, a solidão) estão suspensas, já a verbalização e a evocação destas se mantêm, designadamente em torno das "dores". São as "dores" o idioma, a palavra-chave para comunicar e estabelecer relações de sociabilidade nesse espaço (Quintela, 1999, 2008, 2011).

A decisão de ir até umas termas está associada a episódios críticos da vida - perdas (mortes, divórcios, separações), doenças do próprio ou de familiares. Nas entrevistas realizadas, quando perguntava a alguém quando tinha vindo pela primeira vez, surgia espontaneamente uma narrativa sobre os eventos da vida que, de alguma forma, eram identificados como causas desencadeadoras da doença ou do mal-estar actual. Episódios que nos sugerem que a procura da "cura de águas" e dos espaços onde estas existem é também uma busca de re-criar a vida, uma vez que "tudo se devia curar com água".

\section{Epílogo: águas que curam, recreiam e recriam}

A partir da água, como organizadora de lugares e práticas termais, colocámos a questão de saber se seria possível curar e recrear nos mesmos espaço e tempo medicamente regulados. A questão, porém, parece ter sido de uma forma falaciosa, pois o que a etnografia comparativa nos mostra é que aquilo que está em causa não é a coexistência destas dimensões. O que está em causa é que estas actividades ou dimensões existenciais apenas são desenvolvidas de uma forma fragmentada, digamos que em gavetas (a da doença, a do tratamento, a da religião, a da recreação, a do trabalho) por imposição de regulamentos institucionais e convenções sociais historicamente constituídos.

Em Portugal, a ida para "banhos", para alguns aquistas, sobretudo mulheres, além de responder à motivação de "aliviar as dores do reumatismo" e "atrasar" o desenvolvimento natural da doença e do envelhecimento, permite também aliviar condições existenciais decorrentes de assimetrias sociais, designadamente de género - "ver-se livre dos tachos" - e desenvolver outro tipo de sociabilidade num tempo excepcional em que a recreação tem lugar para recriar o quotidiano. O mediador desta situação é o medicamento água, que só pode ser consumido 
no lugar da sua emergência e que assim obriga a uma deslocação. Tratando-se de uma viagem terapêutica, ela permite uma estadia legitimada pela família e pelos médicos, o que para algumas destas mulheres significa uma oportunidade única de se deslocarem sós. E no lugar das águas, aliviam os seus sofrimentos recreando e recriando. Sofre-se e cura-se? Não, a etnografia, através das narrativas recolhidas, permite dizer que neste contexto fala-se do sofrimento, mas vive-se a recreação e experimenta-se a recriação. Pois apesar de o lugar termal estar organizado de forma a que estas dimensões não se cruzem nos espaços, promove ainda assim actividades que permitem vivê-las em tempos diferentes, como é o caso das noites e da animação termal.

Já a comparação com o contexto brasileiro possibilita constatar que, aqui, estas dimensões coexistem no espaço e no tempo, que os hóspedes assumem a recriação de um tempo para si, e que tratar e recrear estão concebidos de uma forma holística no sentido do bem-estar assumido num balneário total, onde a água é compreendida como tendo uma função de integração de uma cosmologia individual, de relação com o corpo individual e social, que não é o sistema de regulação médica que condiciona, mas sim as condições individuais. Pois não há intermediários, mas apenas um mediador e epítome - a água termal.

Recebido em 15/08/2011

Aceito em 20/08/2011

Maria Manuel Quintela é doutorada em Antropologia Social e Cultural, professora adjunta no Departamento de Saúde Comunitária da Escola Superior de Enfermagem de Lisboa, onde leciona a discipina de mestrado Antropologia e Saúde Pública. Investigadora no Centro Integrado de Antropologia em Rede (CRIA - ISCTE-UL). Tem desenvolvido a sua investigação na área da antropologia da saúde sobre termalismo, água, práticas terapêuticas e dor em Portugal e Brasil. 


\section{Notas}

1. Agradeço ao João Vasconcelos a leitura do texto e as sugestões.

2. Balneário é a designação dada em Portugal ao estabelecimento onde são realizados os tratamentos termais, entre os quais se destacam os "banhos".

3. Estas são as termas portuguesas mais frequentadas nas últimas décadas, com aproximadamente 19.500 aquistas/ano, o triplo das segundas (Termas de Chaves).

4. A pesquisa de campo nas Termas de S. Pedro do Sul foi realizada em 1997, com incursões prévias ao terreno em 1995 e 1996, durante os meses de Verão, correspondendo a seis "quinzenas" (período de um "tratamento termal” em Portugal). No Brasil, o trabalho de campo decorreu durante doze meses (Agosto 2002-2003) e entre Fevereiro e Março de 2004, tendo sido antecedido de visitas exploratórias em Agosto de 2000 e Setembro de 2001 (nesse período usufruí de uma bolsa mista de doutorado da FCT). Nas Termas da Sulfúrea (Portugal), foi realizada durante três quinzenas (meses de Setembro a Novembro de 2003). Outras termas portuguesas foram visitadas no âmbito do doutorado e enquanto investigadora nos projectos coordenados por Cristiana Bastos: "A água como agente terapêutico" (2002-2004) e "Das termas aos spas: reconfigurações de uma prática terapêutica"(2003-2006)

5. O processo de formação desta estância e do hotel em particular está desenvolvido em Quintela (2008).

6. Em 1997 eram aproximadamente 300 habitantes e 19.500 aquistas anuais.

7. Utilizo a denominação de turista, no sentido de Valéne Smith (1989), para quem está no lugar termal mas não faz tratamento, e de "aquista”, uma das categorias locais, para quem faz tratamento. A legislação portuguesa que regula a actividade termal, posteriormente publicada (2004), adopta e define o termo termalista.

8. Até Junho de 1997, o Posto de Turismo estava situado numa sala existente no primeiro andar. Este espaço, em 1885, era denominado Club, e a partir de 1910, de Casino. A sala dedicada primeiramente ao Posto de Turismo e posteriormente à sala de exposições era no tempo do casino a sala de jogos. A sala contígua a esta - o salão de baile - era onde estava instalada provisoriamente a igreja. A nova igreja foi inaugurada em 21 de Maio de 1998 e tem o nome de "Igreja de N. a Senhora da Saúde".

9. O silêncio é mais uma das ambiguidades que cruzam o sítio termal. O barulho feito pelos aquistas, nomeadamente nos espaços de tratamento e mais precisamente na piscina, era a "guerra" para quem ali trabalhava. Pedia-se sistematicamente silêncio, pois, como referiam alguns funcionários, "isto parece uma feira".

10. Hoje, 2011, o Balneário Rainha D. Amélia é o "novo", onde se fazem as terapias de "bem-estar" e Spa Real, possíveis depois da legislação de 2004. O Centro Termal recuperou o nome do primeiro balneário conhecido - D. Afonso Henriques. 
11. Esta senhora referia-se a problemas respiratórios (e as "vias", ao nariz e à garganta).

12. A buvette era uma fonte existente no interior do balneário, onde era distribuída água termal sob a forma de bebida, mediante prescrição médica.

13. Note-se que nessa época a maioria das habitações locais não tinha água quente canalizada.

14. No jornal local, A Tribuna de Lafões, é noticiado o "Banho Santo": "É tradicionalíssimo o 'Banho Santo', que inúmeros forasteiros aqui vêm fazer no dia 29 de Junho. E, no passado 29 de Junho, cá tivemos diversos autocarros transportando os 'fiéis', dando um certo movimento a estas Termas" (Tribuna de Lafões, 15/7/1954). Jorge Dias refere os Banhos Santos como um ritual que se realiza em várias localidades do país no dia de S. João (24 de Junho).

15. A representação das termas como um lugar de natureza e consumo de saúde foi desenvolvido num outro texto (ver Quintela, 2004a).

16. A situação mudou após a realização do trabalho de campo (2002-2004). Desde Junho de 2006, o "termalismo social" e a crenoterapia foram incluídos a par com outras práticas terapêuticas no SUS, mas enquanto "terapia complementar". 


\section{Referências bibliográficas}

FOUCAULT, Michel. 1991. Vigiar e Punir. Petrópolis: Vozes.

GOFFMAN, Erzing. 1966. Asyles. Études sur la Condition Sociale des Malades Mentaux et autres Reclus. Paris: Éditions de Minuit.Petrópolis: Vozes.

GREENWOOD, David J. 1984. "Medicina Intervencionista vs. Medicina Naturalista: História Antropológica de una Pugna Ideológica”. Arxiu d'Etnografia de Catalunya, 3:59-81.

LUZ, Madel T. 2005. "Cultura contemporânea e medicinas alternativas: novos paradigmas em saúde no fim do século XX”. Physis: Revista de Saúde Colectiva, v. 15:145-176.

MACCANELl, Dean. 1976. The Tourist. A new theory of the leisure class. London: The Macmillan Press Ltd.

MACKAMAN, Douglas Peter. 1998. Leisure Settings. Bourgeois culture, medicine and the spa in modern France. Chicago: Chicago University Press.

MALUF, Sónia Weidner. 1996. Les enfants du verseau au pays des Terreiros: Les cultures therapeutiques et spirituels alternatives au sud du Brésil. Tese de Doctarat en Anthropologie Sociale et Ethnologie, EHESS, Paris.

MARRAS, Stélio. 2004. A propósito de águas virtuosas: formação e ocorrências de uma estação balneária no Brasil. Belo Horizonte: Editora da UFMG.

NAIRANDAS, Harisch \& BASTOS, Cristiana (edits.). 2011. "Healing holidays? Itinerant Patients, therapeutic locals and the quest for health”. Anthropology \& Medicine, 18, (1):1-6.

NUTTON, Vivian, 2001 [1993]. "Humoralism”. In: W. F. Bynum \& Roy Porter (eds.). Companion Encyclopedia of The History of Medicine. Vol. I. Londres e Nova York: Routledge. pp. 281-291.

PORTER, Roy. 1990. Medical History of Waters and Spas. London: Welcome Institute for the History of Medicine.

QUINTELA, Maria Manuel. 1999. Curar e Folgar: Etnografia das experiências termais nas Termas de São Pedro do Sul. Master Dissertation, ISCTE, Lisbon.

2001. "Turismo e Reumatismo: etnografia de uma prática terapêutica nas Termas de São Pedro do Sul”. Etnográfica, 5(2):137-158.

. 2004. "Práticas e Saberes Termais em Portugal e no Brasil". História, Ciências, Saúde-Manguinhos, 11, suplem. 1, pp. 239-260. 
2004a. "As termas um lugar de consumo de saúde". In: Maria Cardeira

Silva (org.). Outros trópicos. Novos destinos turísticos. Novos terrenos de antropologia. Lisboa: Livros Horizonte.

2008. Águas que Curam, Águas que 'Energizam': etnografia das práticas terapêuticas termais em Portugal (Sulfúrea) e Brasil (Caldas da Imperatriz). Tese de Doutoramento, Universidade de Lisboa, Lisboa. . 2011. “Seeking 'energy' vs. pain relief in spas in Brazil (Caldas da Imperatriz) and Portugal (Termas da Sulfúrea)”. Anthropology \&Medicine, v. 18, n. 1, Abril. SMITH, Valéne. 1989. "Introduction". In: ___. Hosts and Guests. The Anthropology of Tourism. Philadelphia: University of Pennsylvania Press. pp. 1-17.

TURNER, Byron. 1996. The Body and Society. Explorations in social theory. London: Sage Publications.

WEISZ, George. 2001. "Spas, Mineral Waters, and Hydrological Science in TwentiethCentury France”. Isis, 92:451-483.

ZOLA, Irving Kenneth. 1972. "Medicine as an Institution of Social Control”. Sociological Review, 20(4):170-185. 


\section{Resumo}

O termalismo em Portugal e no Brasil é uma actividade que se desenvolveu no século XX entre a medicina e o turismo, à semelhança do que ocorreu noutros países. Contudo, o processo histórico de institucionalização das "curas de águas" nos dois países assumiu diferentes orientações, em função dos sistemas médicos em que elas estão inseridas, de acordo com a importância dada aos fenómenos que as justificam: curar e recrear. Pretende-se neste artigo discutir a relação entre curar e recrear enquanto dimensões constituintes da formação das estâncias termais e do termalismo em torno da água como eixo estruturante das práticas termais, a partir de uma etnografia comparativa entre Portugal (São Pedro do Sul e Cabeço de Vide) e o Brasil (Caldas da Imperatriz). Através desta comparação são analisadas concepções de saúde, doença, sofrimento, lazer, bem-estar e "tratamento termal", o que permite estabelecer o diálogo entre diferentes terapias e sistemas médicos. É ainda relevante considerar aqui as propriedades atribuídas à água termal por termalistas, médicos e populações locais, tentando compreender em que medida os sistemas médicos que enquadram as práticas termais interferem na experiência termal, fazendo dos "banhos" e da estadia uma oportunidade de curar e/ou, recrear e re-criar quotidianos.

Palavras-chave: termalismo, água, terapias, recrear, curar, Portugal, Brasil, etnografia

\section{Abstract}

Thermalism in Portugal and Brazil is an activity that has developed during the twentieth century midway between medicine and tourism, as has also happened in other countries. However, the institutionalization of water cures in both countries has taken different routes due to the medical systems they were part of. This is related to different ways of emphasizing what characterizes it: either curing or leisure. In this paper I intend to analyze both the relation between curing and leisure as the constituting dimensions of spa settings and the way thermalism, centered on water, organizes thermal practices. I approach these topics using data from my field research in Portugal (São Pedro do Sul and Cabeço de Vide) and in Brazil (Caldas da Imperatriz). I discuss local conceptions of health, illness, suffering, welfare and water cure looking for establishing a dialogue between different therapies and medical systems. Examining the qualities attributed to water by local populations, doctors and spa clients I try to understand how medical systems interfere with the spa experience by making bathing and the very sojourn an opportunity for curing, leisure and recreating everyday life.

Keywords: thermalism, water, therapies, leisure, curing, Portugal, Brazil, ethnography 